\title{
Problemas de corte em duas fases: uma revisão parcial
}

\section{Two-phase cut problems: a partial survey}

\author{
Robinson Samuel Hoto ${ }^{1}$; Fernando Spolador ${ }^{2}$; Marcos Arenales ${ }^{3}$; Nelson Maculan ${ }^{4}$
}

\section{Resumo}

Problemas de Corte e Empacotamento são amplamente estudados e diversos trabalhos a respeito do tema podem ser encontrados na literatura, seja no aspecto puramente teórico, seja nas aplicações práticas. Dentre estes inúmeros problemas, alguns autores relataram ao longo dos anos, casos em que o processo de corte necessita ser efetuado em duas fases. Este trabalho, que é parcial, pretende iniciar uma revisão de problemas de corte em duas fases.

Palavras-chave: Corte e empacotamento. Duas fases. Padrões compartimentados.

\begin{abstract}
Cut and packing problems have been widely studied, and several works on their theory and practical applications can be found in the literature. Among all the problems, authors have reported on cases where the cutting process needs to be done in two phases. The objective of this study is to start a revision on the problems caused by this two-phase cutting process.

Key words: Cut and packing. Two-phase. Compartmentalized patters.
\end{abstract}

\section{Introdução}

O Problema de Corte consiste, basicamente, em determinar a melhor forma de cortar unidades de material (denominadas objetos), de maneira que se produza um conjunto de unidades menores (denominadas itens). Este problema aparece em diversos processos industriais de corte onde os objetos, em geral disponíveis em estoque, correspondem a barras de aço, bobinas de papel, de aço, de alumínio, de filme plástico, etc., chapas metálicas ou de madeira, placas de circuito impresso, lâminas de vidro e fibra de vidro, peças de couro, etc., e os itens, com dimensões especificadas, são em geral encomendados através de uma carteira de pedidos. Similarmente ao Problema de Corte, o Problema de Empacotamento consiste em determinar a melhor forma de arranjar um conjunto de itens dentro de objetos. Exemplos ocorrem nas atividades logísticas de movimentação, armazenagem e transporte de materiais, ao carregar produtos embalados (itens) sobre paletes ou dentro de contêineres e caminhões-cofre (objetos). Ambos os problemas de corte e empacotamento são problemas de otimização intimamente relacionados, referidos na literatura como PCE.

Nas últimas três décadas, inúmeros artigos sobre os PCE foram publicados em diversas revistas especializadas. Salientamos as extensas revisões bibliográficas em Dyckhoff (1990), Sweeney e

\footnotetext{
1 Docente do Departamento Matemática da Universidade Estadual de Londrina, Londrina/PR. E-mail: hoto@uel.br

2 Aluno do Programa de Mestrado do Departamento de Engenharia de Sistemas da Universidade Estadual de Campinas.

3 Aluno do Docente do Departamento de Matemática Aplicada e Estatística da Universidade de São Paulo.

4 Docente do Programa de Engenharia de Sistemas e Computação da Universidade Federal do Rio de Janeiro.
} 
Parternoster (1992), Dowsland e Dowsland (1992), Dyckhoff e Finke (1992), Bischoff e Waescher (1995), Dyckhoff et al. (1997) e Wäscher et al. (2006). A relevância dos PCE advém do crescente estímulo que as indústrias, em geral, têm recebido para otimizar seus processos. Este estímulo ocorre, entre outras causas, pela maior competitividade imposta pelas transformações que têm afetado a ordem econômica mundial.

Em geral, os PCE podem ser formulados como problemas de otimização combinatória, entretanto, eles quase sempre são da classe NP-difícil. Para a resolução destes problemas, podemos contar com aplicativos computacionais comerciais dotados de métodos de otimização gerais, mas, eles não são capazes de resolver problemas desta natureza em tempo de computação razoável. Uma dificuldade adicional é a dimensão dos problemas práticos, que os torna intratáveis através de métodos de otimização exata. Essas verificações indicam a necessidade do desenvolvimento de heurísticas adaptadas aos problemas e possíveis de fornecer uma solução de boa qualidade em tempo computacional coerente. Isso pode ser verificado num grande número de artigos que tratam do assunto.

A grande maioria dos problemas de corte discutidos na literatura ocorrem em uma única fase, isto é, os itens são cortados diretamente dos objetos como ilustra a Figura 1.

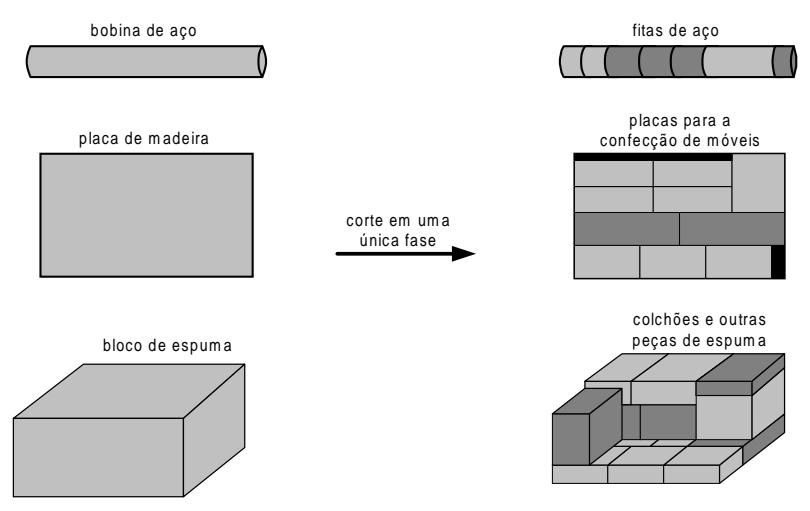

Figura 1. Ilustração de cortes em uma única fase.
Os trabalhos pioneiros de Gilmore e Gomory $(1961,1963)$ tratam da formalização matemática e introduzem a Técnica de Geração de Colunas na resolução de problemas de corte em uma única fase.

Um típico exemplo de corte em duas fases é o corte de bobinas de aço sujeitas a laminação a frio, descrito por Hoto (2001) e Hoto et al. (2006). Nele as bobinas de aço do estoque (objetos) são cortadas (a fase 1 de corte) em sub-bobinas a serem laminadas (objetos intermediários), e estes, por sua vez, são cortados (a fase 2 de corte) em fitas de aço (itens). Na Figura 2, observamos que é a configuração de um padrão de corte (padrão compartimentado) em problemas desta natureza; nele o corte contínuo define dois objetos intermediários (sub-bobinas) e os cortes tracejados definem os itens (fitas de aço). Observe que os itens que compõem o padrão são provenientes de dois grupos distintos (laminações distintas). Os itens de cada grupo irão definir compartimentos (sub-bobinas) que, por sua vez, definirão o padrão compartimentado. Após a primeira fase de corte, são obtidos os objetos intermediários (sub-bobinas que sofrerão laminações distintas). Após a segunda fase de corte, são obtidos os itens (fitas de aço).

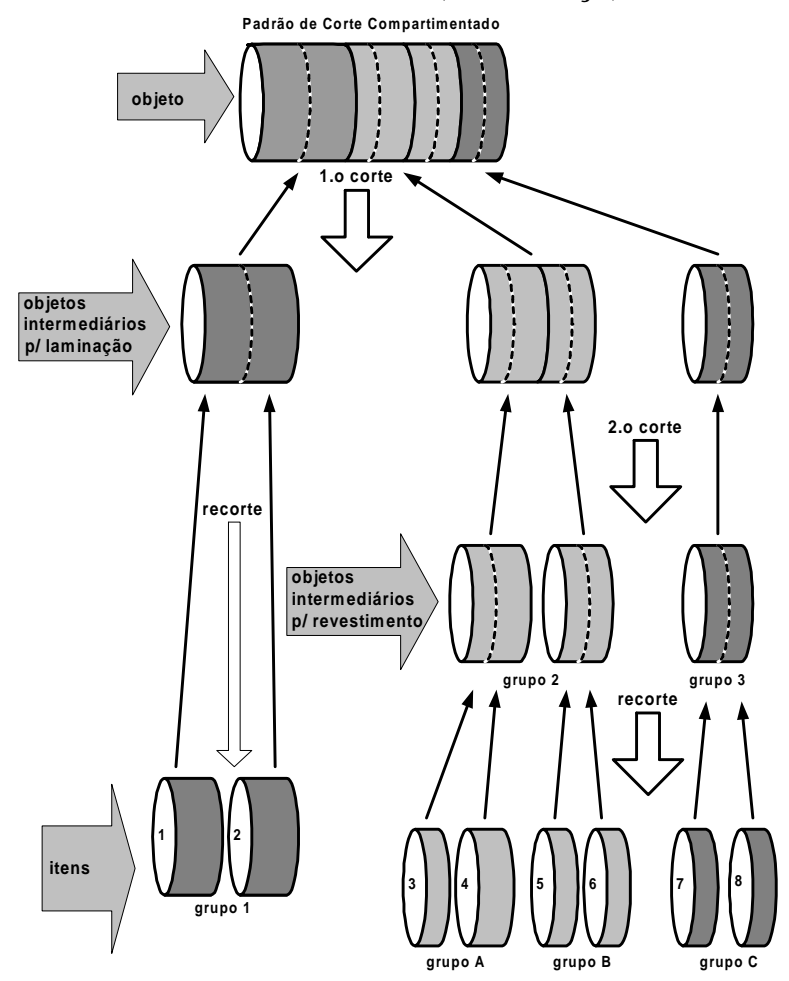

Figura 2. Ilustração de um padrão de corte compartimentado. 
Em certas empresas, após a laminação, algumas fitas recebem um tipo especial de revestimento. Neste caso, além da compatibilidade no processo de laminação, é preciso verificar compatibilidade no processo de revestimento, pois, itens de subconjuntos distintos sofrerão revestimentos distintos. A título de exemplo, considere oito itens (parte de uma carteira) agrupados da seguinte forma:

Tabela 1. Itens sujeitos a laminação e revestimento.

\begin{tabular}{|c|c|c|c|c|c|}
\hline $\begin{array}{c}\text { Grupo A } \\
\text { Revestimento } \\
\text { de Cobre }\end{array}$ & $\begin{array}{c}\text { Grupo B } \\
\text { Revestimento } \\
\text { de Teflon }\end{array}$ & $\begin{array}{c}\text { Grupo C } \\
\text { Revestimento } \\
\text { de Níquel }\end{array}$ & $\begin{array}{c}\text { Grupo 1 } \\
\text { Laminação } \\
\text { Fraca }\end{array}$ & $\begin{array}{c}\text { Grupo 2 } \\
\text { Laminação } \\
\text { Média }\end{array}$ & $\begin{array}{c}\text { Grupo3 } \\
\text { Laminação } \\
\text { Forte }\end{array}$ \\
\hline Itens 3 e 4 & Itens 5 e 6 & Itens 7 e 8 & Itens 1 e 2 & Itens 3, 4, 5 e 6 & Itens 7 e 8 \\
\hline
\end{tabular}

Na Figura 2, ilustramos um padrão de corte viável, segundo o qual os itens 1 e 2 são cortados em duas fases, e os demais são cortados em três fases de corte. Em geral, a última fase de corte é denominada de recorte, desta forma, um problema de corte em $n$ fases (fase 1 de corte + fase 2 de corte $+\ldots+$ fase $n-1$ de corte + recorte) é aquele que apresenta padrões de corte em (n-1)-compartimentados, onde os itens demandados são obtidos após o recorte.

Observe que, em problemas de corte em uma única fase, não existem compartimentos e, segundo a nomenclatura introduzida aqui, os padrões são 0compartimentados.

A construção de um padrão de corte 1compartimentado (ou simplesmente padrão compartimentado) num problema unidimensional pode ser feita com uma categoria especial de mochila, denominada Mochila Compartimentada e introduzida na literatura por Hoto (2001), com realce para os trabalhos de Hoto et al. (1999, 2000, 2002), e de Marques et al. (2000, 2002). Padrões compartimentados podem surgir em problemas bidimensionais como o corte de placas de madeira em indústrias de móveis, caso em que, os objetos intermediários podem, por exemplo, serem padrões estagiados como os descritos por Gilmore e Gomory (1965).

Nas próximas seções, descreveremos abordagens de diferentes autores para problemas de corte em duas fases, obedecendo à seguinte ordem:

- Seção 1 (HAESSLER, 1971 e 1979)

Dois procedimentos serão descritos:no primeiro, o autor apresenta um modelo não-linear para o corte de bobinas de papel, e no outro,o autor discute um problema de corte de bobinas de filmes plásticos.

\section{- Seção 2 (FERREIRA et al., 1990)}

Os autores propõem uma heurística para o corte de bobinas de aço.

- Seção3(CARVALHO; RODRIGUES, 1991, 1994, 1995)

Nestes trabalhos, os autores aplicam o procedimento de geração de colunas no problema do corte de bobinas de aço.

\section{- Seção 4 (PEREIRA, 1993)}

O autor apresenta um modelo de programação linear misto (variáveis inteiras e reais) para o problema do corte de bobinas de aço.

- Seções 5 e 6 (HOTO et al., 1996, 1998, 1999, 2001, 2002, 2003, 2006)

Nestes trabalhos, os autores estudam o problema do corte de bobinas de aço por meio de heurísticas e por geração de colunas, e nele um padrão de corte é construído por meio de uma mochila compartimentada.

- Seção 7 (MARQUES et al., 2000, 2002, 2004)

Os autores estudam o problema da mochila compartimentada com restrições adicionais (caso restrito), essencial para a obtenção de uma solução inteira viável do corte de bobinas de aço.

- Sessão 8 (ZAK, 2002a, 2002b)

O autor propõe uma técnica de geração simultânea de linhas e colunas aplicada na resolução do corte de bobinas de papel. 
- Sessão 9 (CORREIA et al., 2004)

Os autores descrevem suas experiências na modelagem e simulação computacional durante o desenvolvimento do sistema computacional COOL para auxiliar na programação dos cortes de bobinas de papel.

\section{As abordagens de Haessler}

Robert Haessler descreveu, em 1971, um modelo não-linear para o corte de bobinas de papel, num procedimento de duas fases de corte. Em problemas como este estudado por Haessler, fruto de sua tese de doutoramento (HAESSLER, 1968), há uma limitação no número de facas a serem usadas num padrão ou, em outros termos,, o número de itens num padrão de corte deve ser limitado. Esta restrição pode ser considerada ao gerar padrões, entretanto, Haessler optou em modelar o problema, permitindo a geração de padrões que excedessem o limite de itens (o mesmo que a limitação no número de facas). Neste caso, há a necessidade de efetuar um corte, e divide a bobina em sub-bobinas, nas quais o número de itens não excede o limite tolerado e é seguido de um recorte para obter os rolos (itens). Na Figura 3, ilustramos o caso em que o limite de itens é no máximo 5 (o mesmo que 4 facas). Na prática, do total de facas, duas serão utilizadas para aparar as bordas das bobinas e sub-bobinas.
Outra situação técnica que Haessler encontrou, induzindo o corte em duas fases, surge quando o número de bobinas a serem cortadas, segundo um padrão, é muito reduzido. Nesse caso, o número alto de trocas de padrões (HAESSLER, 1975) na máquina de corte prejudica o rendimento da máquina de papel (a que confecciona as bobinas). Para contornar o problema, Haessler propôs cortar e recortar bobinas para aliviar a pressão da produção da máquina de papel sobre a de corte. Nesse aspecto, o problema difere do corte de bobinas de aço, pois, não há necessidade de agrupar os itens, já que não existem restrições quanto à compatibilidade.

Vejamos como Haessler modelou o problema: considere uma carteira de $n$ rolos (itens) de larguras $\ell_{i}$ e demandas $d_{i}$, admita que as bobinas (objetos) tenham comprimento $L$.

Sejam ainda:

$c_{t}$ : (cost of trim loss) custo associado à perda de material por unidade de comprimento;

$c_{p}$ : (cost of processing) custo associado a processamentos de sub-bobinas em relação aos padrões; $a_{i j}^{k}$ : número de itens do tipo $i$ no padrão $j$ tal que, se o número de itens no padrão excede o limite de facas então $k=2$, caso contrário $k=1$. Tendo em vista esta notação, seja $P_{2}$ o conjunto dos índices dos padrões para os quais $k=2$ e $P_{1}$ o conjunto dos índices dos padrões para os quais $k=1$ (Figura 3 );

$x_{j}^{k}$ : número de rolos a serem cortados segundo o padrão $j$, conforme $k=1$ ou $k=2$;

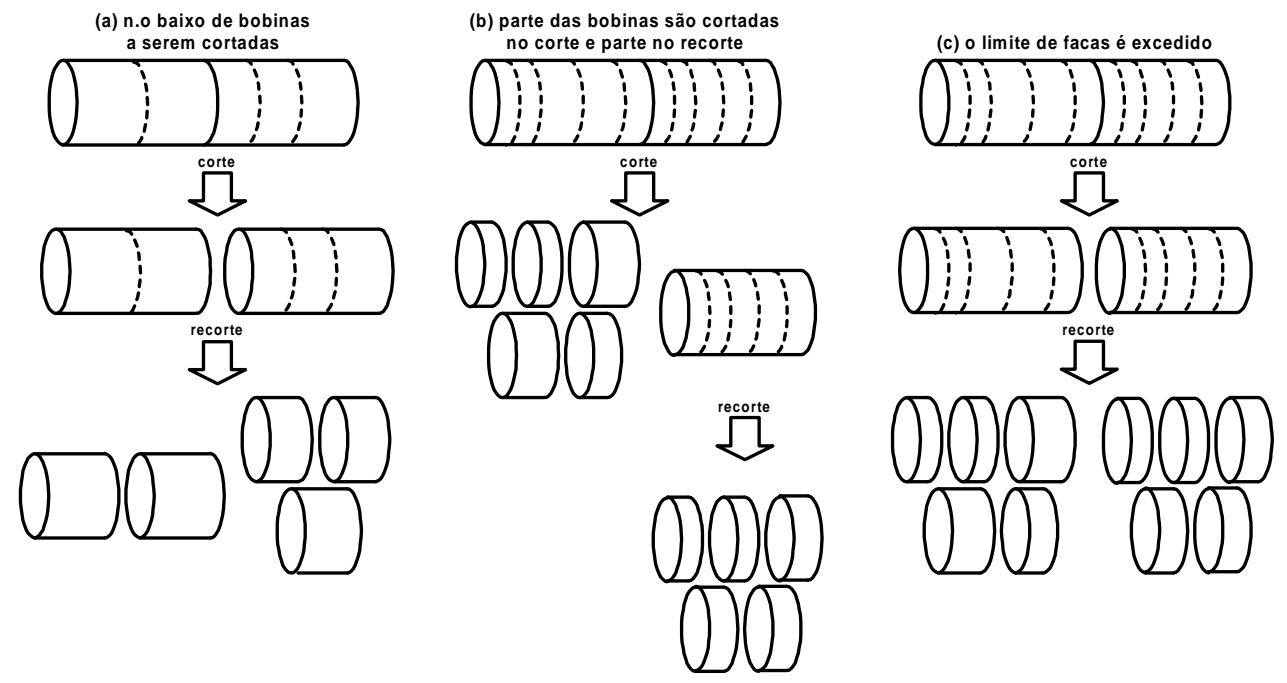

Figura 3. Corte e recorte de bobinas de papel na abordagem de Haessler. 
Observe que um padrão de corte será viável se $\sum_{i=1}^{n} a_{i j}^{k} \ell_{i} \leq L$, com $a_{i j}^{k} \geq 0$ e inteiro para $i=1, \ldots, n$. O custo associado às perdas de material pode ser dado por:

$$
c_{t}\left(\sum_{j \in P_{1}}\left(L-\sum_{i=1}^{n} a_{i j}^{k} \ell_{i}\right) x_{j}^{1}+\sum_{j \in P_{2}}\left(L-\sum_{i=1}^{n} a_{i j}^{k} \ell_{i}\right) x_{j}^{2}\right) .
$$

Haessler observou que o custo do papel não é significativo, se comparado com custos operacionais, de modo que é recomendável otimizar não apenas as perdas, mas, os custos de produção que contemplem as perdas e os processos operacionais. Tendo em vista a pressão exercida pela máquina de papel sobre a máquina de corte, ele sugeriu valores mínimos $L B_{c}$ e $L B_{p} \leq L B_{c}$ para número de bobinas completas e parciais (sub-bobinas) a serem cortadas na máquina de corte, de modo que os seguintes casos foram considerados:

a) se $x_{j}^{1}<L B_{p} \leq L B_{c}$, então $2 x_{j}^{1}$ sub-bobinas serão recortadas na máquina de recorte (Figura 3a), devido ao baixo número de bobinas a serem cortadas;

b) se $L B_{p} \leq x_{j}^{1}<L B_{c}$, então $x_{j}^{1}$ sub-bobinas serão recortadas na máquina de corte e $x_{j}^{1}$ sub-bobinas serão recortadas na máquina de recorte (Figura 3b); c) se $x_{j}^{2}<L B_{p}$, então $2 x_{j}^{2}$ sub-bobinas serão recortadas na máquina de recorte (Figura 3c). Isto é devido ao limite de facas.

Assim, $2 x_{j}^{1}$ sub-bobinas serão processadas conforme os casos 1 e 2 , e este número pode ser computado da seguinte forma:

$$
\sum_{j \in P_{1}} x_{j}^{1} \delta\left(x_{j}^{1}-L B_{p}\right)+\sum_{j \in P_{1}} x_{j}^{1} \delta\left(x_{j}^{1}-L B_{c}\right)
$$

onde $\delta(x-L B)=1$ se $0<x<L B$, e $\delta(x-L B)=0$ em caso contrário. Analogamente, $2 x_{j}^{2}$ sub-bobinas serão processadas conforme o caso 3 ,e este número pode ser computado da seguinte forma:

$$
\sum_{j \in P_{2}} x_{j}^{2}\left(1+\delta\left(x_{j}^{2}-L B_{p}\right)\right) .
$$

Como nem todos os padrões de corte irão ser efetuados em duas fases (Figura 3), Haessler optou por computar o custo da porção de sub-bobinas processadas em relação aos padrões de corte, dado por:

$$
\begin{gathered}
c_{p}\left(\sum_{j \in P_{1}} x_{j}^{1} \delta\left(x_{j}^{1}-L B_{p}\right)+\sum_{j \in P_{1}} x_{j}^{1} \delta\left(x_{j}^{1}-L B_{c}\right)+\right. \\
\left.+\sum_{j \in S_{2}} x_{j}^{2}\left(1+\delta\left(x_{j}^{2}-L B_{p}\right)\right)\right) /\left(\sum_{j \in P_{1}} x_{j}^{1}+\sum_{j \in P_{2}} x_{j}^{2}\right)
\end{gathered}
$$

Na prática, as demandas $d_{i}$ dos itens possuem tolerâncias, de modo que, $d_{i}^{\min } \leq d_{i} \leq d_{i}^{\max }$ para cada $i=1, \ldots, n$, veja (Haessler, 1980). O modelo não-linear proposto por Haessler $(1968,1971)$ é o seguinte:

minimizar

$$
\begin{aligned}
& c_{t}\left(\sum_{j \in P_{1}}\left(L-\sum_{i=1}^{n} a_{i j}^{k} \ell_{i}\right) x_{j}^{1}+\sum_{j \in P_{2}}\left(L-\sum_{i=1}^{n} a_{i j}^{k} \ell_{i}\right) x_{j}^{2}\right)+ \\
& +c_{p}\left(\sum_{j \in P_{1}} x_{j}^{1} \delta\left(x_{j}^{1}-L B_{p}\right)+\sum_{j \in P_{1}} x_{j}^{1} \delta\left(x_{j}^{1}-L B_{c}\right)+\right. \\
& \left.+\sum_{j \in P_{2}} x_{j}^{2}\left(1+\delta\left(x_{j}^{2}-L B_{p}\right)\right)\right) /\left(\sum_{j \in P_{1}} x_{j}^{1}+\sum_{j \in P_{2}} x_{j}^{2}\right)
\end{aligned}
$$

sujeito a:

$d_{i}^{\min } \leq \sum_{j \in P_{1}} a_{i j}^{1} x_{j}^{1}+\sum_{j \in P_{2}} a_{i j}^{2} x_{j}^{2} \leq d_{i}^{\max } ; x_{j}^{1}, x_{j}^{2} \geq 0 e$

inteiros com $i=1, \ldots, n$ e $j \in P_{1} \cup P_{2}$

Para resolver o problema Haessler, desenvolveu uma heurística. Inicialmente ele avalia o total de bobinas e o número médio de itens numa bobina, computando os seguintes valores: $\left(\sum_{i=1}^{n} d_{i} \ell_{i}\right) / L \mathrm{e}$ $L\left(\sum_{i=1}^{n} d_{i}\right) /\left(\sum_{i=1}^{n} d_{i} \ell_{i}\right)$

A seguir, é construído um padrão de corte que satisfaça as seguintes condições:

a) $L-T_{\max } \leq \sum_{i=1}^{n} a_{i j}^{k} \ell_{i} \leq L, a_{i j}^{k} \geq 0 \quad$ e inteiro, onde $T_{\max }$ é a perda máxima tolerada; 
b) $\quad N_{\min } \leq \sum_{i=1}^{n} a_{i j}^{k} \leq N_{\max }$, onde $N_{\min }$ e $N_{\max }$ são respectivamente o número mínimo e máximo de itens tolerados;

c) $\quad a_{i j}^{k} L B \leq d_{i}$, para todo $a_{i j}^{k}>0$, onde $L B$ é o número mínimo de bobinas que devem ser processadas;

O padrão obtido é usado até a exaustão, as demandas dos itens são atualizadas, as estimativas do total de bobinas e do número médio de itens são recalculadas e gera-se um novo padrão, segundo 1 , 2 e 3 . Este processo é repetido até que toda demanda seja satisfeita, ou quando não for possível gerar um padrão, neste caso, 1, 2 e 3 são relaxadas para gerar um padrão, finalizando com uma solução viável para o problema. Haessler citou a dificuldade de resolver o problema como um programa linear, devido à natureza dos padrões de corte. Ele acrescentou que o ajuste dos parâmetros necessários para gerar o próximo padrão, após a atualização das demandas, não consiste em tarefa elementar.

a)

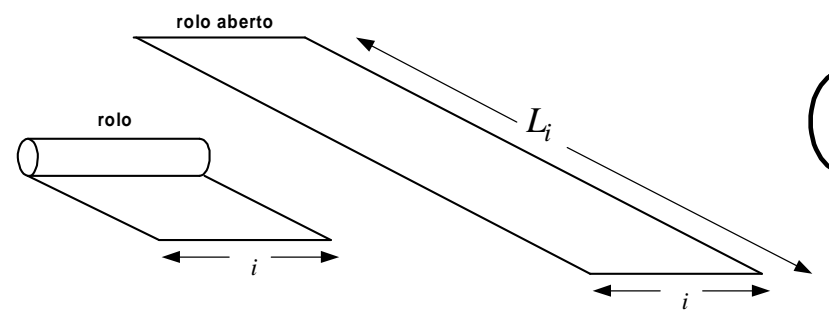

Haessler (1979) estudou também um problema numa indústria de filme plástico, na qual as bobinas do estoque necessitam ser cortadas em sub-bobinas para processamentos em máquinas que não suportam a largura de uma bobina do estoque. Adicionalmente, este problema apresenta uma característica peculiar, pois as demandas são rolos de filmes de largura $\ell_{i} \mathrm{e}$ comprimento $L_{i}$ (Figura 4a), de modo que, além do corte se passar em duas fases o problema é 1.5dimensional (HAESSLER, 1978). Num problema 1.5dimensional, a variável de decisão $x_{j}$, associada ao padrão $j$, não é mais inteira, pois, ela passa a medir o comprimento que será cortado da bobina, segundo o padrão (Figura 4b). Este problema pode ser modelado como um programa linear e novamente a dificuldade consiste em construir um padrão de corte, uma vez que, é preciso decidir a largura e a quantidade de cada sub-bobina (objeto intermediário) a ser cortada de uma bobina (objeto).

Figura 4. a) Rolo de largura $\ell_{i}$ e comprimento $L_{i}$; b) corte 1.5-dimensional.

\section{Ferreira, Neves e Castro e o Corte de Bobinas de Aço}

Na introdução deste trabalho, citamos o problema do corte em bobinas de aço sujeitas à laminação (Figura 2). No trabalho de Ferreira et al. (1990) os autores discutem um procedimento heurístico para o problema em questão: nele $d_{i}$ e $\ell_{i}$ são respectivamente as demandas (em $\mathrm{Kg}$ ) e larguras (em $\mathrm{mm}$ ) das fitas de aço (itens) para $i=1, \ldots, n, \mathrm{e} L$ é a largura (em $\mathrm{mm}$ ) das bobinas do estoque (objetos):
1. Defina os fatores $\mu_{i}=d_{i} \ell_{i}$ para cada $i=1, \ldots, n$ e ordene-os da seguinte forma: $\mu_{1} \geq \mu_{2} \geq \ldots \geq \mu_{n}$.

2. Escolha uma quantidade $p$ de itens segundo o fator $\mu$ do passo 1 ( 5 a 9 primeiros itens foram os valores experimentados). Seja $m$ o número de bobinas intermediárias (objetos intermediários) do padrão que será escolhido e faça $m=3$. Seja $S_{1}$ a largura (em $\mathrm{mm}$ ) da apara retirada das bordas da bobina e $S_{2}$ a largura (em $\mathrm{mm}$ ) da apara retirada das bordas das bobinas intermediárias, assim a largura útil da bobina 
será $L_{\text {útil }}=L-\left(S_{1}+m S_{2}\right)$, onde inicialmente $m=3$.

3. Ordene as larguras dos itens da seguinte forma: $\ell_{1} \geq \ell_{2} \geq \ldots \ell_{p}$.

4. Para cada $j=1, \ldots, p$ gere um padrão de corte segundo a heurística FFD ( $p$ padrões serão gerados).

5. Determine $x_{j} \geq 0$, o total de vezes que cada padrão será usado sem exceder as demandas dos itens. Se nenhum padrão tiver uso, incremente o valor de $p$ e de $m$, recalcule $L_{u \text { útil }}=L-\left(S_{1}+m S_{2}\right)$ e retorne ao passo 3 para gerar novos padrões no passo 4.

6. Defina os fatores $\gamma_{j}=x_{j} /\left(L_{\text {útil }}-\sum_{i=1}^{p} a_{i j}\right)$, onde $a_{i j} \geq 0$ é o número de itens do tipo $i$ no padrấo $j$ e ordene-os da seguinte forma: $\gamma_{1} \geq \gamma_{2} \geq \ldots \geq \gamma_{p}$

7. Selecione o padrão $j^{*}$ que está associado a $\gamma_{1}$ e verifique se ele é viável, segundo as seguintes restrições:

(a) $\left\lceil\frac{L-S_{1}}{L_{\max }+S_{2}}\right\rceil \leq m \leq\left\lfloor\frac{L-S_{1}}{L_{\min }+S_{2}}\right\rfloor$, onde $L_{\min }$ e $L_{\max }$ são respectivamente as larguras mínima e máxima (em $\mathrm{mm}$ ) permitidas para uma bobina intermediária, $\lfloor$. 」 é o maior inteiro menor ou igual a... e $\lceil$. $\rceil$ é o menor inteiro maior ou igual a...

(b) $L_{\min } \leq \sum_{i \in N_{k j^{*}}} a_{i j^{*}} \ell_{i}+S_{2} \leq L_{\max }$, onde $N_{k j^{*}}$ é o conjunto dos índices dos itens que compõem a bobina intermediária $k=1, \ldots, m$. Esses itens devem ser compatíveis entre si, de modo que possam sofrer o mesmo tipo de laminação, do contrário o padrão não será viável;

(c) $\sum_{i \in N_{k^{*}}} a_{i j^{*}} \ell_{i} \leq N_{\max }$, para cada bobina intermediária $k=1, \ldots, m$, onde $N_{\max }$ é o número total de itens permitido numa bobina intermediária (é devido à limitação no número de facas).

Se o padrão $j^{*}$ que está associado a $\gamma_{1}$ não for viável, teste os demais padrões até que um padrão viável seja encontrado, caso contrário incremente o valor de $p$ e de $m$, recalcule $L_{\text {útil }}=L-\left(S_{1}+m S_{2}\right)$ e retorne ao passo 3 para gerar novos padrões no passo 4 .
8. Use o padrão selecionado e atualize as demandas. Se houver demanda remanescente, retorne ao passo 1, caso contrário PARE.

Os autores relataram terem obtido bons resultados práticos com a heurística descrita, entretanto, observamos que a escolha de determinados parâmetros é crítica. Por exemplo, no passo 2, os valores de $r$ e $m$ são iniciados em seus mínimos, e gradativamente incrementados, até que padrões viáveis passem a ser gerados, com isso, em problemas como este um procedimento guloso pode ser desastroso. A geração dos padrões é efetuada por meio da heurística FFD, muito rápida e simples, porém, muito pobre para casos elaborados. Além disso, do mais, ao gerar um padrão, as restrições que determinam o seu caráter de ser compartimentado não são consideradas, de modo que, no passo 7 , é possível que todos os padrões gerados sejam descartados, por violarem justamente estas condições, uma situação indesejada.

\section{Carvalho e Rodrigues e a abordagem de Geração de Colunas para o Corte de Bobinas de Aço}

Em 1991, Carvalho utilizou a Técnica de Geração de Colunas, proposta por Gilmore e Gomory (1961, 1963), na resolução do problema do corte de bobinas de aço sujeitas à laminação a frio. Posteriormente, Carvalho e Rodrigues (1994, 1995) publicaram dois trabalhos, nos quais são descritas as particularidades deste problema de corte em duas fases, bem como pormenores de um sistema computacional para auxiliar na programação dos cortes.

Em sua modelagem matemática, Carvalho (1991) considera $N$ o conjunto dos índices dos itens (fitas de aço) e $J$ o conjunto dos padrões de corte viáveis (padrões compartimentados). Sejam $d_{i}^{\min }$ e $d_{i}^{\max }$ as demandas mínima e máxima de cada item $i \in N$, e $a_{i j} \geq 0$ o número de itens $i$ no padrão $j \in J$. O objetivo será minimizar custos de material e 
processamento, onde $c_{\text {perda }}$ é o custo associado a perda de material, $c_{\text {lam }}$ é o custo associado ao processo de laminação, $c_{1}$ é o custo associado ao acerto de um padrão na primeira fase de corte (as trocas de padrões serão medidas pela função $\delta$ ), por fim, $c_{2}$ é o custo associado ao acerto de padrões na segunda fase de corte. Nessas condições, a função de custo que foi adotada é dada por:

$c_{\text {perda }} \sum_{j \in J} T_{j} x_{j}+c_{\text {lam }} \sum_{j \in J} m_{j} x_{j}+c_{1} \sum_{j \in J} \delta\left(x_{j}\right)+c_{2} m$,

onde $x_{j}$ é o número de vezes que o padrão $j \in J$ é utilizado, $m_{j}$ é o número de bobinas intermediárias no padrão e $m$ é o total de bobinas intermediárias.

Finalmente, o modelo que os autores formularam para o problema é escrito como:

\section{minimizar}

$c_{\text {perda }} \sum_{j \in J} T_{j} x_{j}+c_{\text {lam }} \sum_{j \in J} m_{j} x_{j}+c_{1} \sum_{j \in J} \delta\left(x_{j}\right)+c_{2} m$

sujeito a:

$d_{i}^{\min } \leq \sum_{j \in J} a_{i j} x_{j} \leq d_{i}^{\max } ; x_{j} \geq 0$ e inteiro com $i \in N$

e $j \in J$

Carvalho e Rodrigues (1994, 1995) sugeriram simplificações no modelo anterior, resolveram a relaxação contínua do programa linear resultante, tomaram a solução arredondada para baixo e utilizaram a heurística FFD para completar a demanda.
Para construir um padrão viável (gerar uma coluna), os autores reduziram o espaço de busca, construindo para cada item $i \in N$, todas as bobinas intermediárias homogêneas (compostas por apenas um tipo de item). Assim, para cada $i \in N$, seja o conjunto $K_{i}$ dos índices das bobinas intermediárias homogêneas e $m_{i k}$ o número de itens $i$ na bobina intermediária $k$, os autores apresentaram uma solução para o problema clássico da mochila, (MARTELlO; TOTH, 1990), onde $\pi_{i}$ é um multiplicador Simplex, e $y_{i k}$ é a variável da mochila que decide quantas bobinas intermediárias de índice $k \in K_{i}$ irão compor o padrão:

\section{maximizar}

$\sum_{i \in N} \sum_{k \in K_{i}}\left(\left(\pi_{i}+c_{p e r d a} \ell_{i}\right) m_{i k}-c_{l a m}\right) y_{i k}$

sujeito a:

$\sum_{i \in N} \sum_{k \in K_{i}}\left(m_{i k} \ell_{i}\right) y_{i k} \leq L ; y_{i k} \geq 0$

e inteiro com $i \in N$ e $k \in K_{i}$

Para resolver a mochila anterior, é preciso que as bobinas intermediárias estejam todas definidas. A proposta dos autores foi construir, para cada item $i$, todas as bobinas intermediárias homogêneas (compostas por apenas um tipo de item). A título de exemplo, considere bobinas do estoque com largura de 30 unidades, das quais devem ser cortadas bobinas intermediárias com largura entre 10 unidades e 15 unidades.

Tabela 2. Dados dos itens agrupados segundo suas compatibilidades de laminação.

\begin{tabular}{|c|c|c|c|c|}
\cline { 2 - 5 } \multicolumn{1}{c|}{} & \multicolumn{2}{c|}{ Agrupamento 1 (Laminação Fraca) } & \multicolumn{2}{c|}{ Agrupamento 2 (Laminação Forte) } \\
\hline Item $(i)$ & 1 & 2 & 3 & 4 \\
\hline Utilidade $\left(u_{i}\right)$ & 31 & 17 & 65 & 30 \\
\hline Largura $\left(\ell_{i}\right)$ & 6 & 10 & 11 & 4 \\
\hline
\end{tabular}


Assim, segundo a proposta de Carvalho e Rodrigues (1994, 1995), são examinadas apenas as seguintes bobinas intermediárias:

a) Para o item 1, uma bobina intermediária de largura $\mathrm{L}_{11}=2 \times 6=12$ e utilidade $\mathrm{u}_{11}=62$.

b) Para o item 2, uma bobina intermediária de largura $\mathrm{L}_{21}=1 \times 10=10$ e utilidade $\mathrm{u}_{21}=17$.

c) Para o item 3, uma bobina intermediária de largura $\mathrm{L}_{31}=1 \times 11=11$ e utilidade $\mathrm{u}_{31}=65$.

d) Para o item 4 , uma bobina intermediária de $\operatorname{largura} \mathrm{L}_{41}=3 \times 4=12$ e utilidade $\mathrm{u}_{41}=90$.

Resolvendo a mochila proposta pelos autores, o padrão encontrado é composto por duas unidades da bobina intermediária de largura $L_{41}=3 \times 4=12$, somando uma utilidade de 180 unidades e uma perda de 6 unidades. Neste mesmo exemplo, entretanto, observamos que esta estratégia não considera padrões mais expressivos, por exemplo, os dois itens do agrupamento 2 podem ser combinados para formar uma bobina intermediária de largura 15 , e que pode ser repetida 2 vezes na largura da bobina do estoque.

O padrão compartimentado que acabamos de descrever fornece uma utilidade de 190 unidades e perda nula, podendo ser melhor que aquele gerado pela proposta de Carvalho e Rodrigues. Na Figura 5, estão ilustrados os dois padrões que acabamos de descrever.
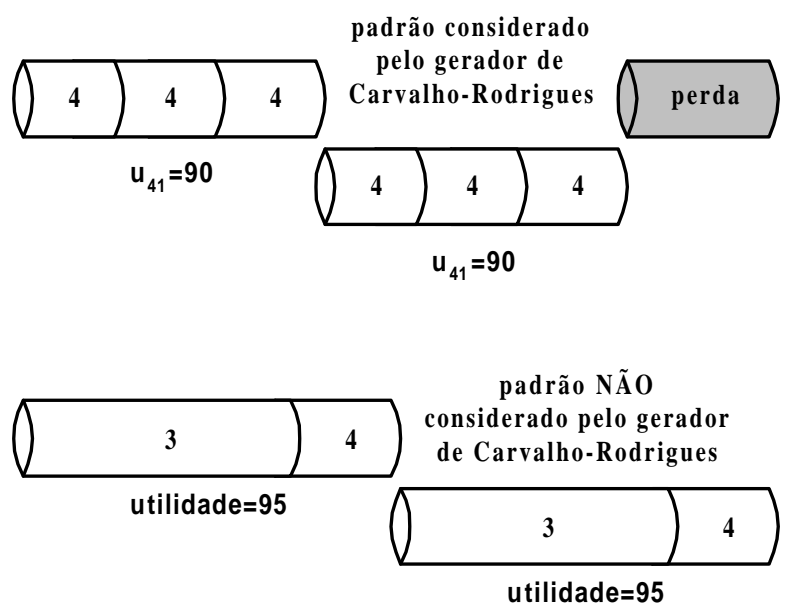

Figura 5. Um padrão gerado (e um descartado) pela abordagem de Carvalho e Rodrigues.
A abordagem de Carvalho e Rodrigues (1994) parece ser muito promissora, entretanto, os autores anularam fortemente o poder combinatório do problema quando reduziram o espaço de busca. Novamente podemos perceber que a dificuldade maior do problema é gerar um padrão compartimentado.

\section{A abordagem de Pereira para a Programação de Fitas Laminadas}

Marcos Pereira (1993) apresentou em sua dissertação de mestrado a descrição de programa linear misto (com variáveis inteiras e reais), cujo objetivo é minimizar o custo pela utilização de uma bobina, bem como, o custo pelo processo de laminação.

$\mathrm{Na}$ explicação do processo, Pereira considerou que os itens de um subconjunto $N-N^{*} \subset N$ podem ser cortados a partir de mais de um tipo de bobina do estoque (é dada a opção de decidir entre alguns tipos de aço), onde $N^{*}$ constitui o subconjunto de índices que não admite esta possibilidade. $\mathrm{O}$ autor reuniu os índices dos itens com compatibilidade para laminação em agrupamentos $N_{s}, s \in G$. Cada bobina $r \in R$ do estoque pode atender um subconjunto $G_{r}$ de agrupamentos $N_{s}$, note que os elementos de $G_{r}$ não são índices, mas agrupamentos $N_{s}$, os quais, por sua vez, são conjuntos de índices de itens com mesma compatibilidade para laminação. Assim, para cada item $i \in N$ existirá um único agrupamento $N_{s}$, com $i \in N_{s}$, de modo que várias bobinas possam atender os itens indexados por $N_{s}$. Este conjunto de bobinas é indexado por $R_{s}$ e os vários tipos de aço são indexados por $h=1, \ldots, H$. Considere $c_{r}$ o custo da bobina $r \in R$. Seja a variável inteira $m_{r s} \geq 0$, que contabiliza o número de bobinas intermediárias da bobina $r \in R$ designadas ao agrupamento $N_{s}$ e $\operatorname{TLam}_{r s}$ o tempo de laminação de uma destas bobinas intermediárias. A função de custo que Pereira modelou é dada por: 


$$
\mid \sum_{r \in R} c_{r} y_{r}+\alpha \sum_{r \in R}\left(\sum_{N_{s} \in G_{r}} \operatorname{TLam}_{r s} m_{r s}\right),
$$

onde $y_{r}$ é igual a 1 se a bobina $r \in R$ foi escolhida, e igual a 0 no caso contrário. $\mathrm{O}$ parâmetro $\alpha$ é para compatibilizar as unidades de custo das bobinas e de tempo de laminação das bobinas intermediárias (ele mede a importância da laminação no processo). As restrições consideradas por Pereira (1993) foram:

a) $\sum_{N_{s} \in G_{r}}\left(\sum_{i \in N_{s}} a_{i r} \ell_{i}\right) \leq y_{r}\left(L_{r}-S_{1}-m_{r s} S_{2}\right)$, para cada $r \in R$. A variável inteira $a_{i r} \geq 0$ contabiliza o número de itens $i$ cortados da boina $r$. e $a$ restrição determina que o total das larguras dos itens cortados da bobina $r \in R$ seja inferior à sua largura útil $L_{r}-S_{1}-m_{r s} S_{2}$ ( $L_{r}$ é a largura da bobina $r$ ).

b) $\sum_{r \in R_{s}} \frac{P_{r}}{L_{r}} a_{i r} \ell_{i} \geq s_{h i} d_{i}$, para cada $i \in N^{*}$, tal que $N_{s}$ é o agrupamento em que $i \in N_{s}$ ( $P_{r}$ é o "peso" da bobina $r$ ). A variável de decisão $u_{h i}$ é igual a 1 se o tipo de aço $h$ foi escolhido para atender o item $i \in N_{k}$, e igual a 0 no caso contrário. Portanto, $\sum_{h=1}^{H} u_{h i}=1$ para cada $i \in N^{*}$ (somente um tipo de aço será escolhido para o item em questão). Observe que a quantidade produzida do item $i$ nunca será inferior a seu pedido.

c) $\sum_{r \in R_{s}} \frac{P_{r}}{L_{r}} a_{i r} \ell_{i} \geq v_{h i}$, para cada $i \in N-N^{*}$, tal que $N_{s}$ é o agrupamento em que $i \in N_{s}$. A variável real $v_{h i} \geq 0$ mede a quantidade produzida do item $i$ no tipo de aço $h$, portanto, $\sum_{h=1}^{H} v_{h i} \geq d_{i}$ para cada $i \in N-N^{*}$ (mais de um tipo de aço poderá ser escolhido para o item em questão). Observe que a quantidade produzida do item $i$ nunca será inferior a seu pedido;

$$
\begin{aligned}
\text { d) } w_{r s} L_{\min } & \leq \sum_{i \in N_{s}} a_{i r} \ell_{i} \leq w_{r s} M \mathrm{e} \\
\left(m_{r s}-1+\varepsilon\right) L_{\max } & \leq \sum_{i \in N_{s}} a_{i r} \ell_{i} \leq m_{r s} L_{\max },
\end{aligned}
$$

para cada $r \in R$ e $N_{s} \in G_{r}$ com $\operatorname{TLam}_{r s}>0$. A variável de decisão $w_{r s}$ é igual a 1 , se a bobina $r \in R$ foi escolhida para atender o agrupamento $N_{s} \in G_{r}$, e igual a 0 no caso contrário. Essas restrições possuem relação com os tamanhos das bobinas intermediárias e com o tempo de laminação, onde $0 \leq \varepsilon<1$ e $M$ é um número grande.

$\mathrm{O}$ autor relaxou as restrições relacionadas com o tempo de laminação e com a designação de tipos de aço alternativos (cada pedido passaria a ser atendido por um único tipo de aço). Ele procurou descrever bounds para a solução de seu modelo e relatou dificuldades, pois algumas bobinas intermediárias possuíam larguras inferiores à largura mínima permitida $\left(L_{\min }\right)$. Além disso, alguns pedidos não eram atendidos. Se observarmos bem, o modelo de Pereira não contempla a compartimentação dos padrões, de modo que, as dificuldades relatadas eram naturais de ocorrer.

\section{A Heurística de Hoto e Arenales para o Corte de Bobinas de Aço}

Hoto (1996) apresentou em sua dissertação de mestrado um procedimento heurístico para o corte de bobinas de aço baseado nas idéias da heurística de Ferreira, Neves e Castro (seção 2), porém, os itens são pré-processados em agrupamentos, viabilizando a geração de um padrão efetivamente factível.

Umimportante aspectoéque as bobinas intermediárias (compartimentos) passaram a ser construídas por meio do seguinte problema da mochila restrito:

$$
\begin{array}{ll}
\text { maximizar } & \sum_{i \in N_{s}} \lambda_{i s} a_{i} \\
\text { sujeito } a: & \sum_{i \in N_{s}} \ell_{i} a_{i} \leq L_{\max } \text { e } \sum_{i \in N_{s}} a_{i} \leq N F-1 \\
& 0 \leq a_{i} \leq \frac{L_{\text {rem }}}{P} \frac{\bar{d}_{i}}{\ell_{i}} ; a_{i} \geq 0 \\
& \text { e inteiro com } i \in N_{s}
\end{array}
$$

$\mathrm{Na}$ mochila anterior, $\lambda_{\text {is }}$ são coeficientes calculados a partir da demanda remanescente $\bar{d}_{i}$, da largura $\ell_{i}$ e da dificuldade em laminar os itens 
de $N_{s}, L_{\max }$ é a largura máxima que uma bobina intermediária pode assumir, $L_{\text {rem }}$ é a largura remanescente de uma bobina do estoque, cujo peso é $P$, finalmente $a_{i}$ é a variável.

Um grande problema na heurística de Hoto e Arenales (1996) é a valorização de bobinas intermediárias de largura máxima, gerando padrões com perdas consideráveis, embora haja algumas fitas que não necessitam de laminação e podem completar esta ociosidade no padrão. Outra alternativa que foi sugerida pelos autores consistia em retirar itens das bobinas intermediárias, que por um lado aumenta a ociosidade, mas, por outro, permite construir uma nova bobina intermediária.

\section{Hoto, Arenales e Maculan e a abordagem de Geração de Colunas com Mochila Compartimentada}

Um problema muito incômodo na prática do corte de bobinas de aço, comum em muitos outros, é a baixa demanda dos itens (Figura 6). Tendo em vista a bordagem 1.5-dimensional de Haessler (1978) (seção 1), Hoto, Maculan e Arenales (1998), sugeriram um modelo que trata o problema em questão via geração de colunas sob o enfoque 1.5-dimensional.

O procedimento não foi levado adiante para o corte de bobinas de aço, porém, motivou os autores a explorarem o problema com geração de colunas. Naturalmente, o grande entrave consistiu na geração dos padrões compartimentados. Em 1999, Hoto, Arenales e Maculan descreveram uma primeira versão da mochila compartimentada, onde não era permitida a replicação de compartimentos (não era permitido que uma mesma bobina intermediária figurasse mais de uma vez no padrão). Os autores descreveram um branch-and-bound com boas soluções, porém, com tempo de processamento que comprometia a geração de colunas. Em 2000, Marques apresentou sua dissertação de mestrado, cujo foco são heurísticas para a resolução de mochilas compartimentadas, e em 2001, Hoto apresentou sua tese de doutoramento, cujo tema é a aplicação de mochilas compartimentadas no corte de bobinas de aço. Em sua tese, Hoto (2001) descreve um novo procedimento (Hoto et al., 2002) para o cálculo de mochilas compartimentadas que melhorou muito a qualidade das soluções até então conhecidas.
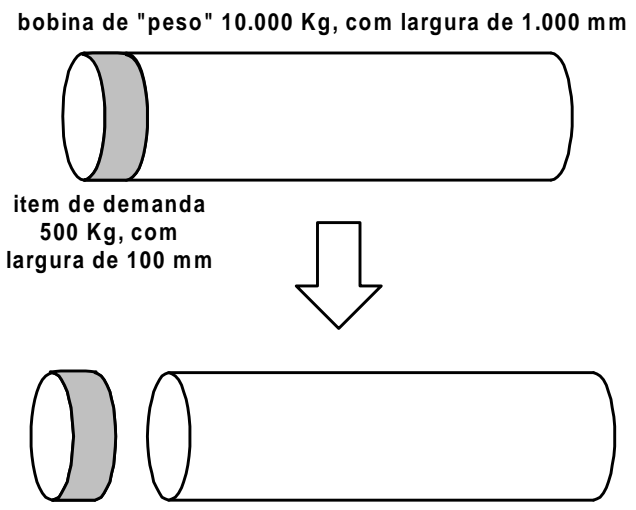

se cortado integralmente da bobina, a produção será $1.000 \mathrm{Kg}$ (o dobro de sua demanda)

Figura 6. Exemplo de baixa demanda no corte de bobinas de aço.

Para descrever uma Mochila Compartimentada Irrestrita, Hoto, Arenales, Maculan e Marques consideraram para cada agrupamento $N_{s}$, o conjunto $V_{s}, s=1, \ldots, q$, dos índices dos compartimentos (bobinas intermediárias) viáveis, de modo que, $V_{s} \cap V_{s^{\prime}}=\varnothing$ para $s, s^{\prime}=1, \ldots, k, s \neq s^{\prime}$. Seja $c_{k}, k \in V_{s}, s=1, \ldots, q$, um custo por utilizar o compartimento $k$, o modelo da mochila compartimentada irrestrita é dado por:

maximizar

$\sum_{k \in V_{1}}\left(\left(\sum_{i \in N_{1}} u_{i} a_{i k}\right)-c_{k}\right) y_{k}+\cdots+\sum_{k \in V_{q}}\left(\left(\sum_{i \in N_{q}} u_{i} a_{i k}\right)-c_{k}\right) y_{k}$

sujeito a:

$\sum_{k \in V_{1}}\left(\sum_{i \in N_{1}} \ell_{i} a_{i k}+S_{2}\right) y_{k}+\cdots+\sum_{k \in V_{q}}\left(\sum_{i \in N_{q}} \ell_{i} a_{i k}+S_{2}\right) y_{k}+S_{1} \leq L$

$\left\lceil\frac{y_{k}}{y_{k}+1}\right\rceil L_{\min } \leq \sum_{i \in N_{s}} \ell_{i} a_{i k}+S_{2} \leq\left\lceil\frac{y_{k}}{y_{k}+1}\right\rceil L_{\max }, k \in V_{s}, s=1, \ldots, q$ 


$$
\begin{aligned}
& a_{i k}, y_{k} \geq 0 \text { e inteiros, } i \in N=N_{1} \cup \cdots \cup N_{q}, \\
& k \in V=V_{1} \cup \cdots \cup V_{q}
\end{aligned}
$$

No modelo anterior, a variável $a_{i k}$ contabiliza o número de itens $i$ no compartimento $k$. A variável $y_{k}$ contabiliza o número de vezes que o compartimento $k$ deve ser considerado na mochila. O parâmetro $u_{i}$ está relacionado com os multiplicadores Simplex na abordagem de geração de coluna, todavia, eles medem uma utilidade do item $i$ na composição da mochila. Por fim, $\lceil$. $\rceil$ é a função menor inteiro maior ou igual a..., observe que $\left[\frac{y_{k}}{y_{k}+1}\right]$ é igual a 1 se $y_{k}>0$ e igual a 0 se $y_{k}=0$.

Para resolver o modelo anterior, os autores construíram todos os compartimentos viáveis, utilizando o algoritmo de Yanasse e Soma (1987) para mochilas com restrição física de igualdade, em seguida resolveram uma mochila irrestrita para decidir quais compartimentos viáveis integrariam o padrão. Os autores provaram que a decomposição descrita conduz à solução ótima da compartimentação. Hoto (2001) propôs substituir os valores das utilidades das mochilas resolvidas pelo algoritmo de Yanasse e Soma por bounds, fornecendo soluções competitivas em qualidade e tempo.

Hoto (2001) usou mochilas compartimentadas para gerar padrões no corte de bobinas de aço sujeitas a laminação. Ele adotou custos $c^{r} m_{I}^{\text {associados à perda }}$ de aço $T_{j}^{r}=\left(L_{r}-S_{1}\right)-\left(\sum_{i=1}^{n} \ell_{i} a_{i j}^{r}\right)-\left(S_{2} \sum_{k=1}^{J} y_{k j}^{r}\right)$ numa bobina $r$ do estoque, e custos $c_{k j}^{r}$ associados à laminação de uma bobina intermediária $k$ definida por um padrão de corte compartimentado $j$. Na expressão de $T_{j}^{r}, n$ é o número total de itens (fitas de aço), $m_{j}^{r}$ é o número total de bobinas intermediárias (compartimentos) na bobina $r$, e a variável $y_{k j}^{r}$ contabiliza o número de bobinas intermediárias $k$ na bobina $r$, segundo o padrão compartimentado $j$. Hoto contabilizou o número de bobinas do tipo $r$, cortadas segundo o padrão $j$, pela variável $x_{j}^{r}$, e admitiu um estoque de bobinas limitado, considerando $e^{r}$ a disponibilidade de bobinas do tipo $r$. Desse modo, o modelo por ele proposto é dado por: minimizar $\sum_{r=1}^{m} \sum_{j=1}^{p_{r}}\left(c^{r} T_{j}^{r}+\sum_{k=1}^{m_{j}^{r}}\left(c_{k j}^{r} y_{k j}^{r}\right)\right) x_{j}^{r}$

sujeito a:

$$
\sum_{r=1}^{m} \sum_{j=1}^{p_{r}} \frac{P_{r}}{L_{r}} \ell_{i} a_{i j}^{r} x_{j}^{r}=d_{i}, i=1, \ldots, n
$$

$$
\begin{array}{ccc}
\sum_{j=1}^{p_{1}} x_{j}^{1} & & \leq e^{1} \\
& \ddots & \vdots \\
& & \sum_{j=1}^{p_{m}} x_{j}^{m} \leq e^{m}
\end{array}
$$

$x_{j}^{r} \geq 0$ e inteiro, $j=1, \ldots, p_{r}, r=1, \ldots, m$

Uma solução inteira viável foi obtida por meio de uma heurística sugerida por Stadtler (1990) e Wäscher (1996), e a esse respeito cabe verificar também Poldi (2003). Hoto (2001) desenvolveu um sistema computacional, em plataforma Windows, denominado RollCut que auxilia na programação dos cortes de bobinas de aço sujeitas à laminação a frio.

O procedimento de geração de colunas com mochilas compartimentadas de Hoto, Maculan e Arenales $(2003,2006)$ obteve soluções superiores em qualidade quando comparada com o procedimentode Carvalho e Rodrigues $(1994,1995)$.

\section{Marques e Arenales e a Mochila Compartimentada Restrita}

O caso restrito da compartimentação de uma mochila, também proposto por Hoto (2001) e explicitada por Marques (2004), prevê as seguintes condições adicionais:

a) a quantidade de cada item $i$ que compõe a mochila deve ser limitada por $d_{i}$ :

$\sum_{s=1}^{q} \sum_{k \in V_{s}} a_{i k} y_{k} \leq d_{i}, i \in N=N_{1} \cup \cdots \cup N_{q}$; 
b) a quantidade de itens em cada compartimento $k$ deve ser limitada por $b_{k}$ :

$$
\sum_{i \in N_{s}} a_{i k} \leq b_{k}, k \in V=V_{1} \cup \cdots \cup V_{q}, s=1, \ldots, q ;
$$

c) a quantidade de compartimentos na mochila deve ser limitada por $c$ :

$$
\sum_{s=1}^{q} \sum_{k \in V_{s}} y_{k} \leq c
$$

Três heurísticas gulosas foram descritas por Marques (2004) e Marques et al. (2000, 2002a, 2002b):

\section{A heurística de decomposição de Marques e} Arenales

Nesta heurística, é construído um compartimento de largura máxima associado a cada agrupamento. Desses compartimentos, serão escolhidos aqueles que melhor montarão a mochila compartimentada. Aqui, como na heurística de Hoto e Arenales (1996) (seção 5), pode haver ociosidade no padrão,o qual é eliminada com a adição de itens que não necessitam de laminação.

\section{A heurística do melhor compartimento de}

\section{Marques e Arenales}

Semelhante à heurística anterior, ele visa à construção de compartimentos com larguras adequadas, para evitar a ociosidade no padrão.

\section{A heurística dos k-melhores compartimentos de}

\section{Marques e Arenales}

Consiste num aperfeiçoamento das heurísticas anteriores, de modo que, ao invés de construir apenas um compartimento associado a cada agrupamento, constroem-se os $\boldsymbol{k}$-melhores compartimentos.Isso pode ser feito por meio do algoritmo de Yanasse et al. (2000), utilizado para determinar as $k$-melhores soluções de uma mochila clássica.

Hoto (2001) também descreveu uma heurística baseada na construção de todos os compartimentos viáveis para a resolução de uma mochila compartimentada restrita. No entanto a variável $y_{k}$ que contabiliza o número de ocorrências do compartimento de índice $k$ na mochila, é considerada binária, assim o compartimento em questão poderá figurar apenas uma vez na mochila.

Atualmente os trabalhos concentram-se numa abordagem de geração de colunas para resolver uma mochila compartimentada restrita. Assim, ao utilizar geração de colunas no corte de bobinas de aço, por exemplo, uma coluna será gerada por outra geração de colunas, isto é, teremos uma geração de colunas embutida noutra. Esse raciocínio possui muita semelhança com o procedimento de Eugene Zak, como veremos a seguir. Outro importante foco é o caso bidimensional de uma mochila compartimentada, que poderia ser aplicada no corte de placas de circuitos impressos. Há também o caso tridimensional, que poderia ser aplicado no empacotamento de caixas, quando houver a necessidade de se criar compartimentos que agrupem caixas com uma mesma característica. Esse é o caso de caixas de um mesmo cliente ou de caixas que contenham produtos específicos que devam ser armazenadas separadamente.

\section{Zak e a abordagem de Geração Simultânea de Linhas e Colunas}

Eugene Zak (2002a, 2002b) explicita o corte de bobinas de papel descrito por Haessler $(1969,1971)$ (seção 1). O autor considerou que as bobinas intermediárias (compartimentos) devem possuir suas larguras limitadas entre um valor mínimo $L_{\min }$ e um valor máximo $L_{\text {max }}$, assim como feito no corte de bobinas de aço. Para modelar o problema, ele distinguiu os padrões compartimentados em dois momentos: na primeira fase de corte (os padrões são construídos para cortar as bobinas do estoque) e na segunda fase de corte (os padrões são construídos para cortar bobinas intermediárias).

Zak (2002a, 2002b) introduziu a variável $x_{j}^{1} \geq 0$ que contabiliza as ocorrências do padrão $j$ da primeira 
fase de corte, e $x_{k}^{2} \geq 0$ que contabiliza as ocorrências do padrão $k$ da segunda fase de corte. A quantidade de itens (bobinas intermediárias) do tipo $\boldsymbol{k}$, cortadas do padrão $j$ da primeira fase de corte, é contabilizada por $a_{k j}^{1} \geq 0$, já a quantidade de itens (rolos de papel) do tipo $\boldsymbol{i}$, cortados do padrão $\boldsymbol{k}$ da segunda fase de corte, é contabilizada por $a_{i k}^{2} \geq 0$. O objetivo do autor foi simplesmente minimizar o total de bobinas do estoque cortadas para atender a demanda $d_{i}$ de cada item, e, assim,ele teve o cuidado de que a utilização de bobinas intermediárias na segunda fase de corte não venha a exceder a respectiva produção na primeira fase. $\mathrm{O}$ modelo que Zak propôs é dado por:

minimizar $\quad \sum_{j} a_{k j}^{1} x_{j}^{1}$

sujeito $a: \quad \sum_{j} a_{k j}^{1} x_{j}^{1} \geq x_{k}^{2}, k=1, \ldots, m$

$\sum_{j} a_{i j}^{2} x_{j}^{2} \geq d_{i} ; x_{j}^{1}, x_{k}^{2} \geq 0 e$

inteiros para todo $j, k$ e $i=1, \ldots, n$

No modelo anterior, além de conhecermos todos itens $i$, necessitamos conhecer todas as bobinas intermediárias (compartimentos) $k$. Zak efetuou a geração das colunas (dos padrões) com o mesmo raciocínio que Hoto et al. (2001, 2002) (seção 6) empregou para resolver mochilas compartimentadas. De fato, a geração dos padrões de Zak pode ser feita por uma mochila compartimentada, cujos itens estão reunidos num único agrupamento, portanto, seus padrões podem ser considerados compartimentados. Um trabalho de comparação entre esses dois procedimentos foi apresentado por Hoto et al. (2005), onde são apresentados resultados com qualidade superior aos de Zak (2002a, 2002b).

Zak considerou ainda a situação em que o número de bobinas intermediárias não é computável e sugeriu a geração simultânea de linhas e colunas (compartimentos e padrões). Embora a cada passo do Simplex revisado saibamos gerar colunas desconhecidas, nada sabemos acerca das linhas desconhecidas. Assim, ele restringiu a busca de bobinas intermediárias, gerando não mais que uma nova bobina intermediária a cada passo do Simplex. Na geração de linhas e colunas simultâneas (bobinas intermediárias e padrões), o autor utilizou o seguinte problema de otimização que gera uma bobina intermediária de largura $\bar{L}_{k}=\sum_{i} \ell_{i} a_{i k}^{2}+S_{2}$ a ser utilizada $a^{1}$ vezes no padrão $j$, onde $\pi_{k}^{1}$ e $\pi_{i}^{2}$ são respectivamente os multiplicadores Simplex da primeira e segunda fase de corte (variáveis duais do modelo principal):

maximizar $\quad \sum_{k} \pi_{k}^{1} a_{k j}^{1}+\left(\sum_{i} \pi_{i}^{2} a_{i j}^{2}\right) a^{1}$

sujeito a: $\quad \sum_{k} L_{k} a_{k j}^{1}+\left(\sum_{i} \ell_{i} a_{k j}^{2}+S_{2}\right) a^{1}+S_{1} \leq L$

$$
L_{\min } \leq \sum_{i} \ell_{i} a_{i j}^{2}+S_{2} \leq L_{\max } ; a_{k j}^{1}, a_{i j}^{2}, a^{1} \geq 0 \text { e inteiros }
$$

Zak considerou $a^{1}=1,2, \ldots,\left\lfloor\frac{L-S_{1}}{L_{\text {min }}}\right\rfloor$ como um parâmetro a ser ajustado, e resolveu o modelo anterior como uma mochila clássica com a restrição adicional $L_{\min } \leq \sum_{i} \ell_{i} a_{i j}^{2}+S_{2} \leq L_{\max }$. Esta idéia também foi explorada por Hoto et al. (2005) e parece ser promissora para o caso restrito de mochilas compartimentadas.

Teoricamente, as limitações impostas por Zak restringiram as escolhas na geração das bobinas intermediárias. Note que, quando não existem novos padrões de corte envolvendo apenas uma nova bobina intermediária, no mínimo duas novas bobinas intermediárias devem ser incluídas num padrão da primeira fase de corte. Pode-se esperar que esta situação seja mais provável no início do Simplex revisado, quando o número de bobinas intermediárias ainda é escasso, por outro lado, à medida que o procedimento gera mais bobinas intermediárias, a situação torna-se menos provável.

\section{Correia, Oliveira e Ferreira e o Sistema COOL}

Correia et al. (2004) descrevem os pormenores da estrutura de um sistema computacional 
denominado COOL, concebido para auxiliar na programação dos cortes de bobinas de papel numa indústria de celulose de Portugal.

Os cortes são efetuados em duas fases, neste caso, uma das restrições responsáveis pelo processo é devida ao número limitado de facas. Para gerar os padrões de corte em duas fases, os autores desenvolveram um algoritmo de enumeração baseado em baseado em ordenação lexicográfica, e suas idéias assemelham-se às utilizadas por Ferreira et al. (1990) (seção 2).

Os padrões de corte gerados pelo algoritmo de enumeração proposto pelos autores alimentam um Problema de Programação Linear Inteira (PPLI), que visa a minimizar a perda de material. Este PPLI é relaxado e os autores utilizam um procedimento de arredondamento das soluções, baseado na análise exaustiva de demandas remanescentes dos itens, isto é, caso exista demanda não atendida, reinicia-se o processo (novos padrões serão gerados) com a demanda remanescente.

Os autores relatam, em seu trabalho, que o sistema COOL foi implantado na Companhia de Papel do Prado, em Portugal, cujos benefícios em termos de redução de custos e melhorias no planejamento operacional foram significativos.

\section{Considerações Finais}

Neste trabalho, iniciamos um texto de revisão sobre corte em duas ou mais fases. Fizemos a descrição parcial de trabalhos da literatura que tratam de problemas de corte em duas fases.

Os primeiros trabalhos são os de Haessler que trata do corte de bobinas de papel e filme plástico (seção 1) neles os itens não necessitam de préprocessamento (não precisam estar agrupados). A seguir foi apresentado o problema do corte de bobinas de aço, estudado por Ferreira, Neves e Castro (seção 2), Carvalho e Rodrigues (seção 3), Pereira (seção 4), Hoto, Arenales e Maculan (seções 5 e 6) e
Marques e Arenales (seção 7); nesse caso, os itens necessitam estar agrupados segundo compatibilidades. Vimos que uma mochila compartimentada encontra um padrão de um problema de corte unidimensional em duas fases (seção 6). O caso restrito desta mochila não apresenta uma resolução elementar, sendo justificável o desenvolvimento de heurísticas (seção 7), tendo em vista sua aplicabilidade em problemas de corte que se passam em duas fases. Nós vimos ainda o trabalho de Zak (seção 8), que sugere um mecanismo de geração de linhas e colunas simultâneas para o corte de bobinas de papel.Nesse modelo, uma linha representa uma bobina intermediária (um compartimento) e uma coluna representa um padrão de corte. Por fim, fizemos um breve relato a respeito do sistema COOL descrito em Correia et al. (2004) que auxilia na programação de cortes em bobinas de papel.

A noção de compartimentação de padrões introduzida por Hoto (2001) pode ser aplicada em problemas de corte em duas fases com ou sem restrições de agrupamento, por exemplo, o corte de bobinas de aço sujeitas à laminação a frio e o de bobinas de papel, respectivamente. Quando não há restrições quanto à compatibilidade de itens, basta considerar um único agrupamento, e em vista deste fato, sugerimos a seguinte nomenclatura para Problemas de Corte em duas Fases:

\section{Corte em duas Fases}

Um PCE possui corte em duas fases quando seus padrões são compartimentados (ou 1compartimentados).

Na Tabela 3, apresentamos um resumo dos procedimentos para corte em duas fases descritas neste texto, e esperamos que este trabalho seja o início de um texto que possa servir como um documento de consulta. 
Tabela 3. Resumo das principais abordagens para Corte em duas Fases.

\begin{tabular}{|c|c|c|}
\hline Problema & Autores & Abordagem \\
\hline Corte de Bobinas de Papel & Haessler (1971) & Heurística \\
\hline Corte de Bobinas de Filme Plástico & Haessler (1979) & Heurística \\
\hline Corte de Bobinas de Aço & Ferreira et al. (1990) & Heurística \\
\hline Corte de Bobinas de Aço & Carvalho e Rodrigues $(1991,1994,1995)$ & Geração de Colunas com Mochila Clássica \\
\hline Corte de Bobinas de Aço & Pereira (1993) & Enumeração \\
\hline Corte de Bobinas de Aço & Hoto (1996) & Heurística com Mochila Clássica \\
\hline Corte de Bobinas de Aço & Hoto (2001) & Geração de Colunas com Mochila Compartimentada \\
\hline Corte de Bobinas de Aço & Hoto et al. $(2003,2006)$ & Geração de Colunas com Mochila Compartimentada \\
\hline Corte de Bobinas de Aço & Marques et al. $(2000,2002)$ & Geração de Colunas com Mochila Compartimentada \\
\hline Corte de Bobinas de Aço & Marques (2004) & Geração de Colunas com Mochila Compartimentada \\
\hline Corte de Bobinas de Papel & Zak (2002a, 2002b) & Geração de Linhas e Colunas \\
\hline Corte de Bobinas de Papel & Correia et al. (2004) & Heurística \\
\hline
\end{tabular}

\section{Agradecimentos}

Este trabalho contou com apoio financeiro do Mestrado em Engenharia Elétrica da Universidade Estadual de Londrina (UEL), da Fundação Araucária de Apoio ao Desenvolvimento Científico e Tecnológico do Paraná e do Conselho Nacional de Desenvolvimento Científico e Tecnológico (CNPq).

\section{Referências}

BISCHOFF, E. E.; WÄSCHER, G. Cutting and packing. European Journal of Operational Research, Amsterdam, v.84, p.503-505, 1995.

CARVALHO, J. M. V. V. Um problema de corte em duas fases. 1991. Tese (Doutorado) - Universidade do Minho, Portugal.

CARVALHO, J. M. V. V.; RODRIGUES, A. J. G. A computer based interactive approach to a two-stage cutting-stock problem. Infor: Information Systems and Opertation Research, Ottawa, v.32, n.4, p.243-252, 1994.
An LP-based approach to a two-stage cuttingstock problem. European Journal of Operational Research, Amsterdam, v.84, p.580-589, 1995.

CORREIA, M. H.; OLIVEIRA, J. F.; FERREIRA, J. S. Reel and sheet cutting at a paper mill. Computers \& Operations Research, New York, v.31, p.1223-1243, 2004.

DOWSLAND, K. A.; DOWSLAND, W. B. Packing problems. European Journal of Operational Research, Amsterdam, v.56, p.2-14, 1992.

DYCKHOFF, H. A typology of cutting and packing problems. European Journal of Operational Research, Amsterdam, v.44, p.145-159, 1990.

DYCKHOFF, H.; FINKE, U. Cutting and packing in production and distribuition. Heidelberg: Springer-Verlag Co., 1992.

FERREIRA, J. S.; NEVES, M. A.; CASTRO, P. F. A twophase roll cutting problem. European Jounal of Operational Research, Amsterdam, v.44, p.185-196, 1990.

GILMORE, P. C.; GOMORY, R. E. A linear programming approach to the cutting stock problem. Operations Research, Baltimore, v.9, n.6, p.849-859, 1961.

A linear programming approach to the cutting stock problem, parth II. Operations Research, Baltimore, v.11, n.6, p.863-888, 1963. 
Multistage cutting stock problems of two and more dimensions. Operations Research, Baltimore, v.13, n.1, p.94-120, 1965.

HAESSLER, R. W. An application of heuristic programming to a nonlinear cutting-stock problem occurring in the paper industry. 1968. (Doctoral) Dissertation - The University of Michigan, Ann Arbor, USA.

A heuristic programming solution to a nonlinear cutting-stock problem. Management Science, Providence, v.17, n.12, p.793-802, 1971.

Controlling cutting pattern changes in one dimensional trim problems. Operations Research, Baltimore, v.23, n.3, p.483-493, 1975.

. A procedure for solving the 1.5: dimensional coil slitting problem. AIIE Transactions, New York, v.10, p.7075,1978 .

Solving the two-stage cutting-stock problem. Omega: The International Journal of Management Science, Elmsford, v.7, n.2, p.145-151, 1979.

A note on computational modifications to the Gilmore-Gomory cutting stock algorithm. Operations Research, Baltimore, v.28, n.4, p.1001-1005, 1980.

HOTO, R. O problema da mochila compatimentada aplicado no corte de bobinas de aço. 2001. Tese (Doutorado) - COPPE/Engenharia de Sistemas e Computação, Universidade Federal do Rio de Janeiro, Rio de Janeiro.

Otimização no corte de peças unidimensionais com restrições especiais de agrupamento. 1996. Dissertação (Mestrado) - ICMC/Universidade de São Paulo, São Carlos, São Paulo.

HOTO, R.; ARENALES, M. Um problema de corte unidimensional com restrições de agrupamento e aplicações industriais. In: OFICINA NACIONAL DE PROBLEMAS DE CORTE E EMPACOTAMENTO - ON PCE, 1., 1996, São Paulo. Anais... São Paulo: IME-USP, 1996. p.31-36.

HOTO, R.; ARENALES, M. N.; MACULAN, N. $O$ problema da mochila compartimentada. Londrina: UEL/ Departamento de Matemática, Centro de Ciências Exatas, 1999. Relatório Técnico.

. The one dimensional compartmentalised cutting stock problem: a case study. European Journal of Operational Research, Amsterdam, 2006. This paper was accepted for publication.

HOTO, R.; MACULAN, N.; ARENALES, M. N. O problema do corte de bobinas de aço via geração de colunas. In: SIMPÓSIO BRASILEIRO DE PESQUISA OPERACIONAL, 30., 1998, Curitiba. Anais...Curitiba, 1998. p.267-268.
Um branch-and-bound para uma versão simplificada do problema da mochila compartimentada. In: SIMPÓSIOBRASILEIRODEPESQUISA OPERACIONAL, 32., 2000, Viçosa. Anais... Viçosa, 2000. p.1824-1836.

HOTO, R.; MACULAN, N.; ARENALES, M. N.; MARQUES, F. P. Um novo procedimento para o cálculo de mochilas compartimentadas. Investigação Operacional, Lisboa, n.22, p.213-234, 2002.

HOTO, R.; MACULAN, N.; MARQUES, F. P.; ARENALES, M. N. Um problema de corte com padrões compartimentados. Pesquisa Operacional, Rio de Janeiro,v.23, n.1, p.169-187, 2003.

HOTO, R.; SPOLADOR, F.; BALDO, T. Sobre a geração simultânea de linhas e colunas em problemas de cote e empacotamento. In: SIMPÓSIO BRASILEIRO DE PESQUISA OPERACIONAL, 37., 2005, Gramado. Anais... Gramado, 2005. p.1767-1779.

MARQUES, F. P. O problema da mochila compartimentada e aplicações. 2004. Tese (Doutorado) - ICMC -Universidade de São Paulo, São Carlos, São Paulo.

MARQUES, F. P.; ARENALES, M. N. O problema da mochila compartimentada. In: SIMPÓSIO BRASILEIRO DE PESQUISA OPERACIONAL, 32., 2000, Viçosa. Anais... Viçosa, 2000. p.803-816.

O problema da mochila compartimentada e aplicações. Pesquisa Operacional, Rio de Janeiro, v.22, n.3, p.285-304, 2002a.

MARQUES, F. P.; ARENALES, M. N.; HOTO, R. O problema da mochila compartimentada: uma revisão dos casos irrestritos e restritos. In: OFICINA NACIONAL DE PROBLEMAS DE CORTE E EMPACOTAMENTO - ON PCE, 6., 2002, Campinas. Anais... Campinas, 2002b. p.112.

MARTELLO, S.; TOTH, P. Knapsack problems: algorithms and computer implementations. Chichester: John Wiley \& Sons, 1990.

PEREIRA, M. A. Uma abordagem matemática para o problema do corte e laminação de fitas de aço. 1993. Dissertação (Mestrado) - UNICAMP, Campinas, São Paulo.

POLDI, K. C. Algumas extensões do problema de corte de estoque. 2003. Dissertação (Mestrado) - ICMC/USP, São Carlos, São Paulo.

SWEENEY, P. E.; PATERNOSTER, E. R. Cutting and packing problems: a cathegorized application-oriented research bibliography. Journal of Operational Research Society, Oxford, v.43, p.691-706, 1992. 
STADTLER, H. A one dimensional cutting-stock problem in the aluminium industry and its solution. European Journal of Operational Research, Amsterdam, v.44, p.209223, 1990.

WÄSCHER, G.; GAU, T. Heuristics for the integer one dimensional cutting-stock problem: a computacional study. OR Spektrum, New York, n.18, p.131-144, 1996.

WÄSCHER, G.; HAUSSNER, H.; SCHUMANN, H. An improved typology of cutting and packing problems. European Journal of Operational Research, Amsterdam. 2006. This paper was accepted for publication.
YANASSE, H. H., SOMA, N. Y. A new enumeration scheme for the knapsack problem. Discrete Applied Mathematics, Amsterdam, v.18, p.235-245, 1987.

YANASSE, H. H., SOMA, N. Y.; MACULAN, N. An algorithm for determining the k-best solutions of onedimensional knapsack problem. Pesquisa Operacional, Rio de Janeiro, v.20, n.1, p.117-134, 2000.

ZAK; E. J. Modeling multistage cutting stock problems. European Journal of Operations Research, Amsterdam, v.141, p.313-327, 2002a.

Row and column generation technique for a multistage cutting stock problem. Computers \& Operations Research, New York, v.29, p.1143-1156, 2002 b. 